\title{
Association between Reported Elder Abuse and Rates of Admission to Skilled Nursing Facilities: Findings from a Longitudinal Population-Based Cohort Study
}

\author{
XinQi Dong ${ }^{a}$ Melissa A. Simon ${ }^{b}$ \\ ${ }^{a}$ Chinese Health, Aging and Policy Program, Rush Institute for Health Aging, Rush University Medical Center, \\ and ${ }^{b}$ Department of Obstetrics and Gynecology, Preventive Medicine and Medical Social Sciences, Northwestern \\ University Medical Center, Chicago, III., USA
}

\section{Key Words}

Elder abuse · Skilled nursing facilities .

Population-based study

\begin{abstract}
Background: Elder abuse is common and is a frank violation of an older adult's fundamental rights to be safe and free of violence. Our prior study indicates elder abuse is independently associated with mortality. This study aims to quantify the relationship between overall elder abuse and specific subtypes of elder abuse and rate of admission to skilled nursing facilities (SNF). Methods: A prospective populationbased study conducted in Chicago of community-dwelling older adults who participated in the Chicago Health and Aging Project (CHAP). Of the 6,674 participants in the CHAP study, 106 participants were reported to the social services agency for elder abuse. The primary predictor was elder abuse reported to the social services agency. The outcome of interest was the annual rate of admission to SNF obtained from the Center for Medicare and Medicaid Services. Poisson regression models were used to assess these longitudinal relationships. Results: The average annual rate of SNF for those without elder abuse was 0.14 (0.58) and for those with elder abuse was 0.66 (1.63). After adjusting for sociodemographic and socioeconomic variables, medical comorbidities, cogni-
\end{abstract}

tive and physical function, and psychosocial wellbeing, older adults who have been abused had higher rates of SNF admission (RR 4.60 (2.85-7.42)). Psychological abuse (RR 2.31 (1.17-4.56)), physical abuse (RR 2.36 (1.19-4.66)), financial exploitation (RR 2.81 (1.53-5.17)) and caregiver neglect (RR 4.73 (3.03-7.40)) were associated with increased rates of admission to SNF, after considering the same confounders. Elder abuse is associated with a higher rate of SNF stay longer than 30 days (RR 6.27 (3.68-10.69)). Conclusion: Elder abuse was associated with increased rates of admission to SNF in this community population. Specific subtypes of elder abuse had a differential association with an increased rate of admission to SNF.

Copyright $\odot 2013$ S. Karger AG, Basel

\section{Introduction}

The World Health Organization (WHO) has declared that elder abuse is a violation of one of a human being's most basic fundamental rights, to be safe and free of violence [1]. In June 2012, President Barack Obama hosted the World Elder Abuse Awareness Day in the White House and proclaimed the national awareness day, in synchrony with the appropriation of the Elder Justice Act and Elder Justice Coordinating Council. Elder abuse in-

\section{KARGER}

E-Mail karger@karger.com

www.karger.com/ger
(C) 2013 S. Karger AG, Basel

0304-324X/13/0595-0464\$38.00/0
XinQi Dong, MD, MPH

Rush University Medical Center

1645 West Jackson, Suite 675

Chicago, IL 60612 (USA)

E-Mail xinqi_dong@ rush.edu 
cludes physical abuse, sexual abuse, psychological abuse, caregiver neglect and financial abuse. National Research Council [2] defines elder abuse as intentional actions that cause harm or create a serious risk of harm, whether or not intended, to a vulnerable elder by a caregiver or other person who stands in a trust relationship to the elder; or failure by a caregiver to satisfy the elder's basic needs or to protect the elder from harm.' Available data suggest that 1 out of 10 US elderly persons experience abuse each year, and many of them experience it in multiple forms $[3,4]$. In addition, recent data from US Adult Protective Services (APS) Agencies depict an increasing trend in the reporting of elder abuse [5]. This trend is particularly alarming as the literature suggests that elder abuse is associated with an increased risk of morbidity and mortality $[6-8]$.

Currently, there are major gaps in our understanding in the health services utilization among those who are victimized. Prior case reports suggest that elder abuse victims frequently use health services. Recent studies have provided conflicting results in health services utilization among those reported to the APS $[9,10]$. Skilled nursing facilities (SNF) and long-term custodial care are significant contributors to the rapidly increasing cost in our healthcare system, especially among those cognitively and physically frail. Recent biomedical and technological advances have significantly increased our ability to develop preventive services and disease prevention strategies. Older adult victims often are put in a situation that may threaten their health and safety, which further predisposes their likelihood to have more frequent utilization of health services. Despite contribution of recent work, we are not aware of any epidemiological study that has systematically examined the prospective association between elder abuse and rate of admission to SNF in a community-dwelling population. Improved understanding of important factors that predict SNF use could inform strategies for social services practice, public policy as well as clinical practice $[11,12]$.

In this study, we used Anderson's [13, 14] behavioral model to guide our understanding of elder abuse and health services use as a function of predisposing, enabling, and need variables. Predisposing variables are individual characteristics of those with elder abuse that influence the propensity to use health services (SNF), such as demographic (age, sex, and race). Enabling variables are factors that influence access to healthcare services such as education and income. Needs variables refer to healthcare needs or medical comorbidities, both those perceived by the victims of elder abuse (subjective) and those evaluated by healthcare professional (objective) and encompassing physical, cognitive and other psychosocial factors. The need component of the behavioral model is considered to be the most immediate cause of health services use and often could serve as moderators in the relationship between elder abuse and health service use.

In this study, we examined (1) the relationship between elder abuse and the rate of admission to SNF within a prospective population-based cohort and (2) the relationship between specific subtypes of elder abuse and SNF in the same cohort. We hypothesized that older adults who are abused have increased rates of admission to SNF, even after controlling for potential confounders, and that the rate of admission to SNF differs by the specific subtypes of elder abuse.

\section{Methods}

\section{Population}

Chicago Health and Aging Project (CHAP) is a populationbased cohort study that examines risk factors for Alzheimer's disease. Its participants include residents of three adjacent neighborhoods on the south side of Chicago. More in-depth details of the study design of CHAP have been previously published $[15,16]$. Data collection occurred in cycles, each lasting 3 years, with each cycle ending as the succeeding cycle began. Each cycle consisted of in-person interviews in the participants' homes.

\section{Predictor: Elder Abuse}

In the current study, participants include those who were enrolled between 1993 and 2010 and had valid data on SNF history $(\mathrm{n}=6,674)$ obtained from the Center for Medicare and Medicaid Services (CMS). From this cohort, we identified a subset of participants $(n=106)$ who were reported to social services agencies for elder abuse. Elder abuse cases were reported by friends, neighbors, family, social workers, city workers, healthcare professionals, and others. The reports were usually triggered by concerns for the health and safety of the older adult in their environment, which would initiate a number of different services to help the affected person. All CHAP participants received structured, standardized in-person interviews that included assessment of health history. Written informed consent was obtained and the study was approved by the Institutional Review Board at Rush University Medical Center.

In Illinois APS, the definition used for abuse includes physical abuse, sexual abuse, psychological abuse, neglect and financial exploitation. Physical abuse is defined as inflicting physical pain or injury upon an older adult. Sexual abuse is touching, fondling, intercourse, or any other sexual activity with an older adult, when the older adult is unable to understand, unwilling to consent, threatened or physically forced. Psychological abuse involves verbal assaults, threat of abuse, harassment or intimidation. Confinement is restraining or isolating an older adult, other than for medical reasons. Neglect is a caregiver's failure to provide an older adult with life's necessities, including, but not limited to, food, clothing, shelter or medical care. Willful deprivation is defined as 
willfully denying an older adult medication, medical care, shelter, food, a therapeutic device or other physical assistance, and thereby exposing that person to the risk of physical, mental or emotional harm. Financial exploitation includes the misuse, or withholding of an older adult's resources by another, to the disadvantage of the elderly person or the profit or advantage of someone else.

We matched data from CHAP participants to elder abuse cases reported to social services agencies from 1993 through 2010. Matching was based on an algorithm that compared the following information: date of birth, sex, race, exact home address, zip codes, and the home phone number. Matching was performed twice to increase accuracy. This resulted in 106 older CHAP participants who matched a social service agency record. If a CHAP participant was found to be reported more than once, we selected the first report.

\section{Outcome: Admission to Skilled Nursing Facility}

SNF records were abstracted from the Medicare Standard Analytic Files (SAFs) obtained from the CMS. CMS has approved the Study Protocol and Data Use Agreement with the CHAP study to obtain CMS data. The CHAP study has successfully linked participants and their CMS claims data for the Medical Denominator Files and the SAF files which contain the record of SNF utilization. For each participant, we have abstracted and summarized SAF files on their number of SNF admission during the study period. From the total cohort of 6,674 participants, there were 1,721 who had SNF admission, of whom 1,678 for no abuse cases (25\%) and 43 for elder abuse (41\%). The primary outcome of SNF is the calculated annual rate of SNF admission during the study period.

\section{Covariates}

Covariates were selected based on predisposing, enabling and needs factors from the overarching conceptual framework. Demographic variables include age (in years), sex (men or women), race (self-reported: non-Hispanic Black versus non-Hispanic White), income categories, and education (years of education completed). Self-reported medical conditions include the history of diagnosis of hypertension, diabetes mellitus, stroke, coronary artery disease, hip fracture, and cancer.

Cognitive and physical function has been associated with an increased risk for elder abuse [17-20]. A battery of four cognitive function tests was administered: the Mini-Mental State Examination (MMSE) [21], immediate and delayed recall of brief stories in the East Boston Memory Test [22] and the Symbol Digit Modalities Test [23]. To assess global cognitive function with minimal floor and ceiling artifacts, we constructed a summary measure for global cognition based on the $\mathrm{z}$-score of the individual cognitive tests described above (range -3.49 to $1.73, \alpha=0.87$ ).

Physical function was assessed using the self-reported Katz Index of Activities of Daily Living (Katz ADL) (range 0-6, $\alpha=0.85$ ), which measured limitations in an individual's ability to perform basic self-care tasks [24]. Physical function was also assessed by direct performance testing, which provided a comprehensive objective and detailed assessment of certain abilities [25]. Lower-extremity performance tests consisted of measures of tandem stand, timed walk, tandem walk, and ability to rise to a standing position from a chair (score range $0-15, \alpha=0.74$ ). Most of these performance tests were used in the Established Populations for Epidemiologic Studies of the Elderly (EPESE) project [25] and in other large-scale studies of disability.
Psychosocial factors have been associated with an increased risk for elder abuse [26-30]. Psychosocial factors included assessment of depressive symptoms, social network and social engagement. Symptoms of depression (range $0-10, \alpha=0.76$ ) were measured using a modified version [31] of the Center for Epidemiologic Studies of Depression Scale (CES-D) [32]. Social network (range 0-81) was summarized as the total number of children, relatives, and friends seen at least monthly [33]. Social engagement was assessed by asking how often older adults participate in social activities outside of house, such as religious activities, museums, library and senior centers (range $0-8, \alpha=0.40$ ).

\section{Analytic Approach}

Descriptive characteristics were provided across the sociodemographic variables, socioeconomic variables, medical conditions, cognitive function, physical function and psychosocial factors. Our independent variables of interest were reported elder abuse, confirmed elder abuse, and different subtypes of elder abuse. Our outcome of interest was annual rate of SNF, which was summarized for those with and without elder abuse as well as for specific subtypes of elder abuse. We used the z-test to compare differences in the rate of admission to SNF between groups.

Poisson regression models were used to quantify the relation between elder abuse variables and rate of SNF admission. We used a series of models to consider these relationships, taking into consideration the potential confounders. In our core model (model A), we included age and sex. In addition, we added to the prior model the variables of race, education, and income to quantify the association of elder abuse and SNF outcomes (model B). Moreover, we added to the prior model common medical comorbidities of hypertension, coronary artery disease, stroke, hip fracture, cancer, and diabetes as well as levels of cognitive function and physical function (model C). Finally, models were repeated controlling for additional psychological and social measures (model D). We also repeated the prior models $\mathrm{A}-\mathrm{D}$ to examine the association between confirmed elder abuse and rate of admission to SNF.

In addition, we examined the association between elder abuse subtypes of psychological abuse, physical abuse, caregiver neglect (summary measure of neglect, willful deprivation and confinement) and financial exploitation with the rate of admission to SNF by repeating models $\mathrm{A}-\mathrm{D}$. Moreover, we conducted analyses comparing those with multiple forms of elder abuse (physical abuse and psychological abuse, or caregiver neglect and financial exploitation, etc.) adjusting for the same confounding factors. Due to the low rate, we did not analyze sexual abuse cases. Lastly, we examined the association between elder abuse and the rate of admission to SNF stay longer than 30 days. Rate ratio (RR) and 95\% confidence interval (CI) were reported for the regression models. Analyses were carried out using SAS ${ }^{\circledR}$, Version 9.2 (SAS Institute Inc., Cary, N.C., USA).

\section{Results}

\section{Baseline Characteristics}

There were a total of 6,674 CHAP participants in this study and 106 participants were identified by social services agencies for elder abuse from 1993 to 2010. Among 
Table 1. Elder abuse and rate of admission to SNF

\begin{tabular}{|c|c|c|c|c|c|c|}
\hline & Mean & SD & Median & $\begin{array}{l}\text { Interquartile } \\
\text { range }\end{array}$ & z-Test & $\mathrm{p}$ value \\
\hline No elder abuse (reference group) & 0.14 & 0.58 & 0.00 & 0.06 & & \\
\hline Reported elder abuse & 0.66 & 1.63 & 0.00 & 0.07 & 4.61 & $<0.001$ \\
\hline Confirmed elder abuse & 0.68 & 1.32 & 0.00 & 0.67 & 4.16 & $<0.001$ \\
\hline \multicolumn{7}{|l|}{ Specific subtypes of elder abuse } \\
\hline Caregiver neglect & 1.01 & 2.14 & 0.00 & 0.83 & 4.37 & $<0.001$ \\
\hline Psychological abuse & 0.43 & 1.12 & 0.00 & 0.26 & 1.63 & 0.102 \\
\hline Physical abuse & 0.69 & 1.32 & 0.25 & 0.72 & 3.74 & $<0.001$ \\
\hline Financial exploitation & 0.53 & 1.19 & 0.00 & 0.45 & 2.87 & 0.004 \\
\hline \multicolumn{7}{|l|}{ Multiple types of elder abuse } \\
\hline One type & 0.66 & 1.90 & 0.00 & 0.42 & 2.61 & 0.009 \\
\hline Two or more types & 0.67 & 1.36 & 0.00 & 0.61 & 3.74 & $<0.001$ \\
\hline
\end{tabular}

the 106 reported cases of elder abuse, there were 50 cases of caregiver neglect, 45 cases of psychological abuse, 19 cases of physical abuse, and 65 cases of financial exploitation cases. There were a total of 51 cases with single type of elder abuse and 55 cases of two or more types of elder abuse. The mean age of those with admissions to SNF was 75.7 years (standard deviation $(\mathrm{SD})=7.3$ years) and those without SNF was 72.0 (6.5). Those with SNF admissions compared to those without SNF admissions were more likely to be women (63 vs. $37 \%$ ), Black older adults (54 vs. $45 \%)$, and lower levels of income (5.1 (2.5) vs. 5.7 (2.6)), but with similar levels of education (12.4 (3.6) vs. 12.5 (3.5) years), respectively.

The annual rate of SNF admission for those not reported for elder abuse was $0.14(0.58)$ and for those with reported elder abuse it was $0.66(1.63)$ ( $\mathrm{z}$-test, $4.61, \mathrm{p}<0.001$ ) (table 1). Similar results were found for confirmed elder abuse. In addition, the annual rate of SNF admission for psychological abuse was 0.43 (1.12), for physical abuse it was 0.69 (1.32), for caregiver neglect it was 1.01 (2.14), and for financial exploitation it was 0.53 (1.19). For elder abuse victims who suffered one type of elder abuse the annual rate of SNF admission was $0.66(1.90)$ and for two or more types of elder abuse it was 0.67 (1.36).

\section{Elder Abuse and Rate of SNF Admission}

In the initial Poisson regression model adjusting for age and sex, we found that reported elder abuse strongly predicted the increased rate of SNF admission (RR 3.49 (2.44-5.02)) (table 2, model A). After adding race, education and income, the association diminished slightly (RR 5.75 (3.75-8.83)) (model B). Next, after we added common chronic medical conditions of hypertension, diabe- tes, stroke, cancer, thyroid disease, myocardial infarction as well as levels of cognitive function and physical function to the model (model C), the association remained significant (RR 2.88 (1.94-4.27)). In the last model (model D), after adjusting for psychological and social wellbeing factors, reported elder abuse remained an independent predictor of increased rate of SNF admission (RR 3.05 (2.09$4.44)$ ). For the covariates of interest, higher age, men, Whites, lower income, medical comorbidities, cognitive impairment, physical disability, and depressive symptoms are all associated with an increased risk for SNF admissions. For confirmed elder abuse, in the fully adjusted model, our data indicate that elder abuse is associated with an increased rate of SNF admission (RR 4.60 (2.85-7.42)).

\section{Specific Subtypes of Elder Abuse and SNF Admission}

To quantify the relation between specific subtypes of elder abuse and SNF admission, we used the same Poisson regression model adjusting for similar factors as above. In the fully adjusted model, psychological abuse (RR 2.31 (1.17-4.56)), physical abuse (RR 2.36 (1.194.66)), financial exploitation (RR 2.81 (1.53-5.17)), and caregiver neglect (RR 4.73 (3.03-7.40)) were independently associated with an increased rate of SNF admission. Moreover, for elder abuse victims who suffered one type of abusive act (RR $2.75(1.60-4.74))$ and two or more forms of abusive acts (RR 3.42 (2.04-5.77)), there was also a significantly greater rate of SNF admissions (table 3 ).

\section{Elder Abuse and Length of Stay at SNF Longer than 30 Days}

Lastly, we examined the relationship between elder abuse and length of SNF that that are longer than 30 days 
Table 2. Reported and confirmed elder abuse and the risk of SNF

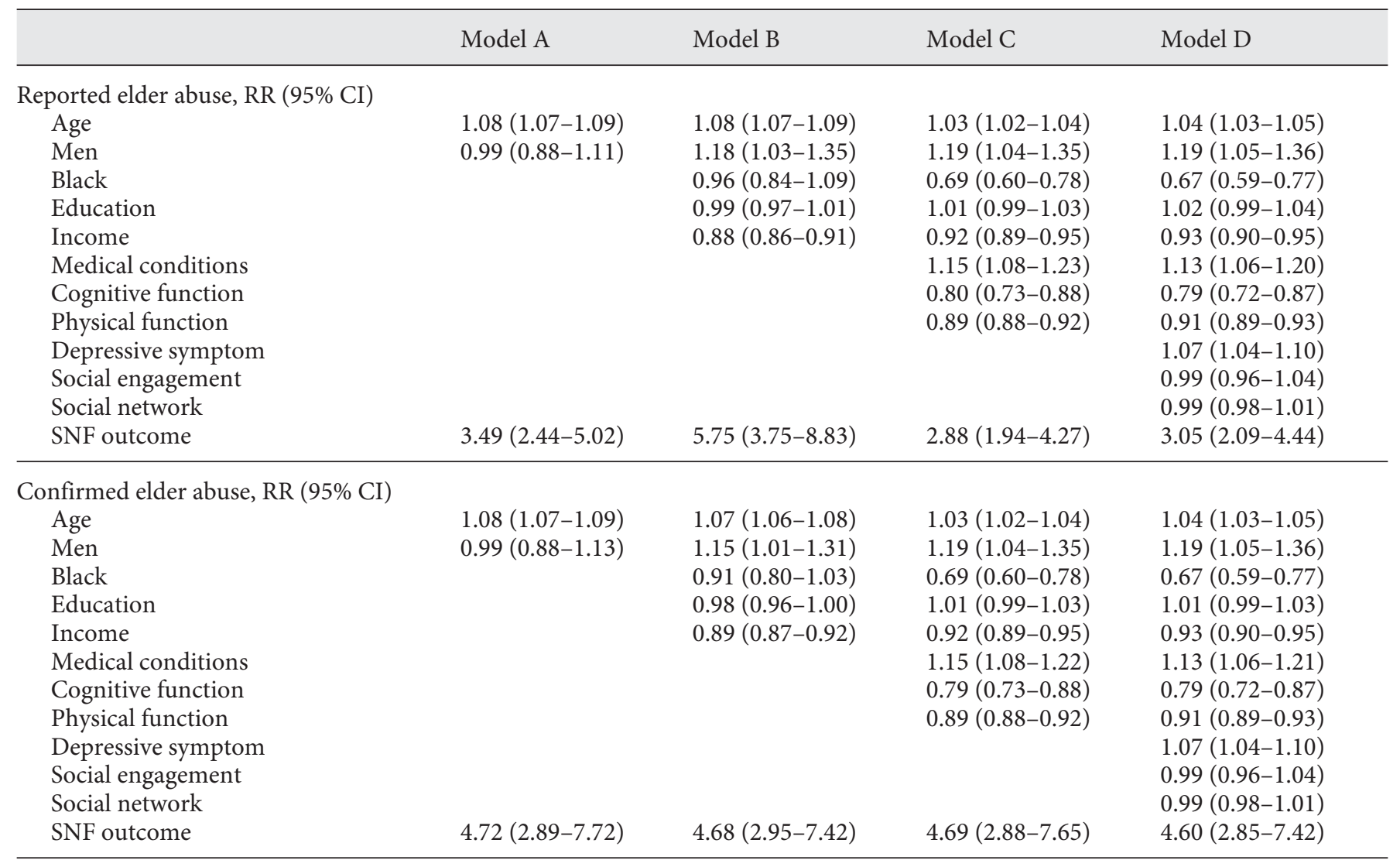

(table 4). In the fully adjusted model, reported elder abuse (RR 3.28 (2.11-5.09)) and confirmed elder abuse (RR 6.27 (3.68-10.69)) are both associated with an increased rate of SNF stay longer than 30 days. For the specific subtypes of elder abuse, physical abuse (RR 3.07 (1.19-7.94)), financial exploitation (RR 2.91 (1.51-5.64)) and caregiver neglect (RR 4.89 (2.63-9.12)) were all associated with an increased rate of SNF stay longer than 30 days.

\section{Discussion}

Within the context of a prospective population-based study of 6,674 older adults from an urban geographicallydefined community, we found that reported and confirmed elder abuse was independently associated with the increased rate of admission to SNF. In addition, specific subtypes of elder abuse had differential associations with the rate of SNF admissions. Lastly, elder abuse is associated with an increased rate of SNF stay longer than 30 days.
Our findings expand the results of prior work of elder abuse and health services utilization. A prior study has matched the Connecticut Social Services Agency data to the EPESE to identify those who have encounters with APS $(n=44)$ [34], which had an increased risk of longterm custodial nursing home placement. Other studies have also indicated that older adults who have encounters with APS agencies have a higher rate of health services utilizations $[35,36]$. However, a retrospective casecontrol study of 131 APS cases found no significant differences in healthcare utilizations compared to matched controls [37].

This present study expands on the results of prior studies of elder abuse and health services utilization. First, our study is the largest population-based study to systematically examine the prospective association between elder abuse and rate of admission to SNF, demonstrating a significant association between elder abuse and an increased rate of admission to SNF. The study population is racially/ethnically and socioeconomically diverse and has been well characterized for more than 17 years, which 
Table 3. Elder abuse subtypes and SNF

\begin{tabular}{|c|c|c|c|}
\hline Models & $\mathrm{RR}$ & $95 \% \mathrm{CI}$ & $\mathrm{p}$ value \\
\hline \multicolumn{4}{|c|}{ Psychological abuse } \\
\hline $\mathrm{A}$ & 2.59 & $1.32-5.09$ & 0.006 \\
\hline $\mathrm{B}$ & 2.47 & $1.28-4.79$ & 0.007 \\
\hline $\mathrm{C}$ & 2.34 & $1.18-4.61$ & 0.014 \\
\hline $\mathrm{D}$ & 2.31 & $1.17-4.56$ & 0.016 \\
\hline \multicolumn{4}{|c|}{ Physical abuse } \\
\hline A & 2.88 & $1.52-5.44$ & 0.001 \\
\hline $\mathrm{B}$ & 2.76 & $1.48-5.17$ & 0.002 \\
\hline $\mathrm{C}$ & 2.29 & $1.17-4.49$ & 0.016 \\
\hline $\mathrm{D}$ & 2.36 & $1.19-4.66$ & 0.013 \\
\hline \multicolumn{4}{|c|}{ Financial exploitation } \\
\hline A & 3.11 & $1.83-5.28$ & $<0.001$ \\
\hline $\mathrm{B}$ & 2.84 & $1.67-4.82$ & $<0.001$ \\
\hline $\mathrm{C}$ & 2.48 & $1.32-4.67$ & 0.005 \\
\hline $\mathrm{D}$ & 2.81 & $1.53-5.17$ & $<0.001$ \\
\hline \multicolumn{4}{|c|}{ Caregiver neglect } \\
\hline A & 6.00 & $3.89-9.24$ & $<0.001$ \\
\hline $\mathrm{B}$ & 5.50 & $3.55-8.53$ & $<0.001$ \\
\hline $\mathrm{C}$ & 4.80 & $3.04-7.59$ & $<0.001$ \\
\hline $\mathrm{D}$ & 4.73 & $3.03-7.40$ & $<0.001$ \\
\hline \multicolumn{4}{|c|}{ One type of elder abuse } \\
\hline A & 3.11 & $1.89-5.09$ & $<0.001$ \\
\hline $\mathrm{B}$ & 2.89 & $1.77-4.73$ & $<0.001$ \\
\hline $\mathrm{C}$ & 2.47 & $1.39-4.39$ & 0.002 \\
\hline $\mathrm{D}$ & 2.75 & $1.60-4.74$ & $<0.001$ \\
\hline \multicolumn{4}{|c|}{ Two or more types of elder abuse } \\
\hline $\mathrm{A}$ & 4.14 & $2.43-7.04$ & $<0.001$ \\
\hline $\mathrm{B}$ & 3.80 & $2.26-6.42$ & $<0.001$ \\
\hline $\mathrm{C}$ & 3.49 & $2.06-5.92$ & $<0.001$ \\
\hline $\mathrm{D}$ & 3.43 & $2.04-5.77$ & $<0.001$ \\
\hline
\end{tabular}

Models A-D: (A) adjusted for age, sex; (B) adjusted for A + race, education and income; $(C)$ adjusted for $B+$ hypertension, diabetes, stroke, cancer, hip fracture, coronary artery disease, MMSE, East Boston Memory Test, East Boston Delayed Recall, and Symbol Digit Modality Test, physical function, and (D) adjusted for C + depressive symptoms, social engagement, social network.

contribute to the potential generalizability of our study findings. Second, our study considered a wide range of potential confounders in the association between elder abuse and rate of admission to SNF. Older adults who are placed in SNF tend to be older, have lower levels of socioeconomic status, have more medical comorbidities, have lower levels of cognitive and physical health, and greater levels of psychosocial distress. However, adjusting for these factors did not ameliorate the significant association between elder abuse and rate of admission to SNF.

Third, the present study is the first population-based study able to examine the specific subtypes of elder abuse
Table 4. Association between elder abuse and length of stay at SNF longer than 30 days

\begin{tabular}{|c|c|c|c|}
\hline Models & $\mathrm{RR}$ & $95 \%$ CI & $\mathrm{p}$ value \\
\hline \multicolumn{4}{|c|}{ Reported elder abuse } \\
\hline A & 3.85 & $2.53-5.85$ & $<0.001$ \\
\hline B & 3.41 & $2.22-5.23$ & $<0.001$ \\
\hline $\mathrm{C}$ & 3.02 & $1.89-4.80$ & $<0.001$ \\
\hline $\mathrm{D}$ & 3.28 & $2.11-5.09$ & $<0.001$ \\
\hline \multicolumn{4}{|c|}{ Confirmed elder abuse } \\
\hline A & 6.14 & $3.46-10.90$ & $<0.001$ \\
\hline $\mathrm{B}$ & 5.76 & $3.31-10.03$ & 0.001 \\
\hline $\mathrm{C}$ & 6.30 & $3.66-10.87$ & $<0.001$ \\
\hline $\mathrm{D}$ & 6.27 & $3.68-10.69$ & $<0.001$ \\
\hline \multicolumn{4}{|c|}{ Psychological abuse } \\
\hline A & 2.23 & $0.85-5.88$ & 0.105 \\
\hline B & 2.13 & $0.81-5.61$ & 0.125 \\
\hline $\mathrm{C}$ & 2.31 & $0.95-5.61$ & 0.064 \\
\hline $\mathrm{D}$ & 2.17 & $0.88-5.36$ & 0.095 \\
\hline \multicolumn{4}{|c|}{ Physical abuse } \\
\hline A & 3.50 & $1.32-9.25$ & 0.012 \\
\hline $\mathrm{B}$ & 3.50 & $1.32-9.27$ & 0.012 \\
\hline $\mathrm{C}$ & 3.22 & $1.22-8.49$ & 0.018 \\
\hline $\mathrm{D}$ & 3.07 & $1.19-7.94$ & 0.021 \\
\hline \multicolumn{4}{|c|}{ Financial exploitation } \\
\hline A & 3.48 & $1.89-6.39$ & $<0.001$ \\
\hline B & 2.98 & $1.62-5.49$ & $<0.001$ \\
\hline $\mathrm{C}$ & 2.52 & $1.25-5.10$ & 0.010 \\
\hline $\mathrm{D}$ & 2.91 & $1.51-5.64$ & 0.001 \\
\hline \multicolumn{4}{|c|}{ Caregiver neglect } \\
\hline A & 5.60 & $3.27-9.58$ & $<0.001$ \\
\hline $\mathrm{B}$ & 5.14 & $2.89-9.12$ & $<0.001$ \\
\hline $\mathrm{C}$ & 4.83 & $2.60-8.97$ & $<0.001$ \\
\hline $\mathrm{D}$ & 4.89 & $2.63-9.12$ & $<0.001$ \\
\hline \multicolumn{4}{|c|}{ One type of elder abuse } \\
\hline $\mathrm{A}$ & 3.38 & $1.96-5.82$ & $<0.001$ \\
\hline $\mathrm{B}$ & 2.88 & $1.64-5.05$ & $<0.001$ \\
\hline $\mathrm{C}$ & 2.21 & $1.15-4.27$ & 0.018 \\
\hline $\mathrm{D}$ & 2.63 & $1.43-4.82$ & 0.002 \\
\hline \multicolumn{4}{|c|}{ Two or more types of elder abuse } \\
\hline A & 4.32 & $2.14-8.73$ & $<0.001$ \\
\hline $\mathrm{B}$ & 4.03 & $2.01-8.09$ & $<0.001$ \\
\hline $\mathrm{C}$ & 4.36 & $2.28-8.35$ & $<0.001$ \\
\hline $\mathrm{D}$ & 4.07 & $2.09-7.89$ & $<0.001$ \\
\hline
\end{tabular}

Models A-D are as explained in table 3.

and multiple forms of elder abuse with respect to rate of SNF admission. Although all subtypes of elder abuse were associated with an increased rate of SNF admission, our finding suggests that caregiver neglect had the highest $\mathrm{RR}$ for SNF admission. It is conceivable that those who are neglected may have the greatest caregiver needs, which might predispose them to be at greater risk for SNF admission. Improved understanding of the potential elder 
abuse-specific associations would contribute to our understanding to the potential causal association between elder abuse and health services utilization. This information could be useful in future prevention and intervention strategies for elder abuse victims [38, 39].

Lastly, SNF is enormously expensive and in part responsible for the soaring healthcare costs. With recent biomedical and technological advances, it is critical for healthcare professionals, social services agencies and other relevant disciplines to identify older adults at risk for abuse and intervene before the deterioration occurs in extremes to warrant SNF care. As we enter the era of healthcare reform, improved understanding of factors that increases SNF could also have significant implications for public policy and clinical practice.

The causal mechanisms between elder abuse and SNF admission remain incomplete. We considered a series of sociodemographic and socioeconomic characteristics, medical comorbidities, cognitive function, physical function, and psychosocial factors. However, adjustments for these factors did not change the relationship between elder abuse and rate of admission to SNF. It is conceivable that elder abuse victims with medical comorbidities are more likely to be admitted to SNF. At the same time, it is conceivable that elder abuse victims with medical comorbidities are more likely to be involved with APS, which may place the vulnerable older adults in SNF to ensure their safety and wellbeing. Future studies are needed to explore these relationships.

Metabolic abnormalities, nutritional deficiencies, infections, injuries or trauma may be other factors that could interact with consequences of elder abuse, which could account for the association between elder abuse and rate of admission to SNF. However, we do have information on these factors to explore the mechanisms. Severity of chronic medical conditions (i.e. ejection fraction in patients with congestive heart failure, or force expiratory volume in patients with emphysema, etc.) could be another important factor in determining the causal mechanisms between elder abuse and health services utilization. In addition, it is conceivable that elder abuse victims could have exacerbation of the existing medical conditions (i.e. congestive heart failure or emphysema exacerbation, etc.) which could predict a higher rate of admission to SNF. However, we do not have measures in our existing data to further elucidate these relations. Future studies are needed to explore the interactions of these variables with elder abuse with respect to SNF.

Our study also has a number of limitations. First, it focused on the reporting of elder abuse as the primary predictor, which had a relatively small sample size compared to the entire cohort. Elder abuse was not ascertained uniformly for all members of the population, but only for participants referred to the social services agency because someone suspected problems. Elder abuse is underreported, although the precise rate of underreporting is unknown, although evidence suggests that only 1 out of 10-25 cases are actually reported to APS. In our study, the potential for underreporting is likely to have underestimated the strength of the relationship between elder abuse and rate of admission to SNF. At the same time, given the possibilities of these reported elder abuse cases being the most egregious, it is possible that we are overestimating the strength of these associations. Future studies are needed to uniformly collect elder abuse indicators in a representative population to rigorously examine these associations.

Second, ascertainment of SNF and long-term custodial care may not be complete. A limitation of using CMS data is selective underdetection of some services including use of Veterans Administration facilities and some managed care episodes. This underdetection of our outcomes of interest tends to underestimate the frequency and rate of admission to SNF in our study population. Third, our study does not have available data on other relevant health services utilization measures (i.e. rate of physician visit, home health visit, utilization of intensive care services, etc.). This information could help to explain the causal mechanisms between elder abuse and use of SNF. Future studies of these relations deserve further exploration.

Fourth, there are likely to be additional factors that may account for the increased rate of SNF use. In addition, improved understanding of the interaction between elder abuse and the severities of medical conditions and other health-related factors such as physical disability could contribute toward the causal mechanisms between elder abuse and rate of admission to SNF. More specifically, future studies are needed to elucidate the interactions among severity of medical conditions and its exacerbations, impairment in specific activities and instrumental activities in daily living and mobility, with respect to the relationship between elder abuse and health services utilizations. Regrettably, we do not have data to consider these additional confounders in our analyses, which may in-part account for the findings in this report. However, this study sets the foundation for future study of elder abuse to fully examine these issues.

Our findings have practical and clinical implications for healthcare professionals in prevention, detection, 
and management of elder abuse. In the healthcare setting, professionals focus on preventive care and rigorous management of chronic medical conditions in order to avoid unnecessary use of SNF. Healthcare professionals should consider screening for elder abuse among older patients who are in SNF and may have frequent encounters with healthcare systems. In addition, healthcare professionals should be educated on the importance of screening for elder abuse and could be integrated into the routine history-taking for older patients in diverse clinical settings across the continuum. Careful monitoring of potential elder abuse victims could help healthcare professionals to more closely monitor the patients and devise strategies to prevent unnecessary health service use.

Our findings could have important implications for multiple and other disciplinary forms that work with older adults who have experienced abuse, neglect and exploitation. In addition to geriatricians, other relevant allied healthcare professionals and disciplines who work closely with elder abuse victims could be in unique positions to further monitor factors that may exacerbate the unnecessary use of the health services such as SNF. In addition, it is important for all relevant disciplines to monitor the severity or the progression of abusive, neglectful and exploitative behaviors towards older adults. Early identification of signs and symptoms of elder abuse and devising targeted prevention and intervention strategies could prevent deterioration of abusive acts into more severe forms, which in turn could potentially decrease the unnecessary utilization of healthcare services. Moreover, we should leverage family members, social workers, health professionals, and public health and community organizations to create an interdisciplinary approach to comprehensively understand, care and prevent elder abuse in our contemporary society.

Future research is needed to explore temporal associations of targeted risk/protective factors associated with specific subtypes of elder abuse in community-dwelling populations. Future studies are needed to explore the longitudinal association of specific subtypes of elder abuse to the rate as well as the intensity of other forms of health services utilization as well as to improve our understanding of the mediating factors associated with elder abuse and health services use, particularly relating to vulnerability factors like physical disability. Also needed are studies examining the role of potential interventions to prevent elder abuse and/or reduce elder abuse severity with respect to health services utilization outcomes in diverse populations.

Association between Reported Elder

Abuse and Rates of Admission to SNF

\section{Conclusion}

In sum, elder abuse is independently associated with an increased rate of admission to SNF within the context of a longitudinal epidemiological study of older adults. In addition, different subtypes of elder abuse had a differential association with the rate of admission to SNF. Moreover, elder abuse is associated with a SNF stay longer than 30 days. Future studies will also be necessary to adequately determine the specific causal mechanisms of the racial/ethnic and gender differences between elder abuse and health services utilizations in the general population. National policy efforts are needed to collectively push for the issues of elder abuse in our contemporary society.

\section{Acknowledgments}

This work was supported by National Institute on Aging grant (R01 AG042318, R01 MD006173, R01 AG11101 \& RC4 AG039085), Paul B. Beeson Award in Aging (K23 AG030944), The Starr Foundation, John A. Hartford Foundation and The Atlantic Philanthropies.

\section{Disclosure Statement}

The authors have no conflicts of interest to disclose.

References

1 World Health Organization: World report on violence and health. http://www.who.int/ violence_injury_prevention/violence/ world_report/en/summary_en.pdf., 2002.

2 National Research Council: Elder Mistreatment: Abuse, Neglect and Exploitation in an Aging America. Washington, The National Academies Press, 2003.

3 BeachSR,SchulzR,CastleNG, RosenJ:Financial exploitation and psychological mistreatment among older adults: differences between African-Americans and non-African-Americans in a population-based survey. Gerontologist 2010;50:744-757.

-4 Acierno R, Hernandez MA, Amstadter AB, Resnick HS, Steve K, Muzzy W, et al: Prevalence and correlates of emotional, physical, sexual, and financial abuse and potential neglect in the United States: The National Elder Mistreatment Study. Am J Public Health 2010; 100:292-297.

5 Teaster PB, Dugar T, Mendiondo M, Abner EL, Cecil KA, Otto JM: The 2004 Survey of adult protective services: abuse of adults 60 years of age and older. www.elderabusecenter.org/pdf/ research/apsreport030703.pdf (accessed April 4, 2007). 
6 Dong X: Medical implications of elder abuse and neglect.Clin Geriatr Med 2005;21:293-313.

7 Dong X, Simon MA, Mendes de Leon C, Fulmer T, Beck T, Hebert L, et al: Elder self-neglect and abuse and mortality risk in a community-dwelling population. JAMA 2009; 302:517-526.

$>8$ Dong X, Simon MA, Beck T, McCann J, Farran C, Laumann EO, et al: Elder abuse and mortality: the role of psychological and social wellbeing. Gerontology 2011;57:549-558.

9 Franzini L, Dyer CB: Healthcare costs and uti- 2 lization of vulnerable elderly people reported to adult protective services for self-neglect. J Am Geriatr Soc 2008;56:667-676.

10 Lachs MS, Williams CS, O’Brien S, Pillemer KA: Adult protective service use and nursing home placement. Gerontologist 2002;42:734-739.

11 Dong X, Simon MA: Enhancing national policy and programs to address elder abuse. JAMA 2011;305:2460-2461.

12 Mosqueda L, Dong X: Elder abuse and self-neglect: 'I don't care anything about going to the doctors ... to be honest'. JAMA 2011;306:532540 .

13 Andersen R: Societal and individual determinants of medical care utilization in the United States. Milbank Mem Fund Q Health Soc 1973;51:95-124.

14 Andersen R: Revisiting the behavioral model and access to medical care: does it matter? J Health Soc Behav 1995;36:1-10.

15 Bienias JL, Beckett LA, Bennett DA, Wilson RS, Evans DA: Design of the Chicago Health and Aging Project (CHAP). J Alzheimers Dis 2003;5:349-355.

16 Evans DA, Bennett DA, Wilson RS, Bienias JL, Morris MC, Scherr PA, et al: Incidence of Alzheimer disease in a biracial urban community: relation to apolipoprotein $\mathrm{E}$ allele status. Arch Neurol 2003;60:185-189.

17 Dong X, Simon MA, Beck TT, Evans DA: Decline in cognitive function and elder mistreatment: findings from the Chicago Health and Aging Project. Am J Geriatr Psychiatry 2013 (E-pub ahead of print).

18 Dong X, Simon MA, Evans DA: Decline in physical function and risk of elder abuse reported to social services in a communitydwelling population of older adults. J Am Geriatr Soc 2012;60:1922-1928.
19 Dong X, Simon MA, Rajan K, Evans DA: Association of cognitive function and risk for elder abuse in a community-dwelling population. Dement Geriatr Cogn Disord 2011;32: 209-215.

20 Dong X, Simon MA, Evans DA: A population-based study of physical function and risk for elder abuse reported to social services agency: findings from the Chicago Health and Aging Project. J Appl Gerontol 2013 (E-pub ahead of print).

1 Folstein MF, Folstein SE, McHugh PR: 'Minimental state'. A practical method for grading the cognitive state of patients for the clinician. J Psychiatr Res 1975;12:189-198.

22 Albert M, Smith LA, Scherr PA, Taylor JO, Evans DA, Funkenstein HH: Use of brief cognitive tests to identify individuals in the community with clinically diagnosed Alzheimer's disease. Int J Neurosci 1991;57:167-178.

23 Smith A: Symbol Digit Modalities Test Manual. Los Angeles, Western Psychological, 1984.

24 Katz S, Akpom CA: A measure of primary sociobiological functions. Int J Health Serv 1976; 6:493-508.

25 Guralnik JM, Simonsick EM, Ferrucci L, Glynn RJ, Berkman LF, Blazer DG, et al: A short physical performance battery assessing lower extremity function: association with self-reported disability and prediction of mortality and nursing home admission. J Gerontol 1994;49: M85-M94.

26 Dong X, Simon MA, Odwazny R, Gorbien MJ: Depression and elder abuse and neglect among community-dwelling Chinese elderly population. J Elder Abuse Neglect 2008;20: 25-41.

27 Dong X, Beck TT, Simon MA: Loneliness and mistreatment of older Chinese women: does social support matter? J Women Aging 2009; 21:293-302.

28 Dong X, Simon MA: Is greater social support a protective factor against elder mistreatment? Gerontology 2008;54:381-388.
29 Dong X, Simon MA, Gorbien M, Percak J, Golden R: Loneliness in older Chinese adults: a risk factor for elder mistreatment. J Am Geriatr Soc 2007;55:1831-1835.

30 Dong X, Simon MA: Gender variations in the levels of social support and risk of elder mistreatment in a Chinese community population. J Appl Gerontol 2010;29:720-739.

31 Kohout FJ, Berkman LF, Evans DA, CornoniHuntley J: Two shorter forms of the CES-D (Center for Epidemiological Studies Depression) depression symptoms index. J Aging Health 1993;5:179-193.

32 Radloff L: The CES-D scale: a self-report depression scale for research in the general population. Appl Psychol Meas 1977;1:385401.

33 Cornoni-Huntley J, Brock DB, Ostfeld A, Taylor JO, Wallace RB: Established Populations for Epidemiological Studies of the Elderly Resource Data Book (NIH Publ. No. 862443). Washington, US Department of Health and Human Services, 1986.

-34 Lachs MS, Williams CS, O’Brien S, Pillemer KA: Adult protective service use and nursing home placement. Gerontologist 2002;42:734739 .

35 Schonfeld L, Larsen RG, Stiles PG: Behavioral health services utilization among older adults identified within a state abuse hotline database. Gerontologist 2006;46:193-199.

-36 Lachs MS, Williams CS, O’Brien S, Hurst L, Kossack A, Siegal A, et al: ED use by older victims of family violence. Ann Emerg Med 1997;30:448-454.

-37 Franzini L, Dyer CB: Healthcare costs and utilization of vulnerable elderly people reported to adult protective services for self-neglect. J Am Geriatr Soc 2008;56:667-676.

38 Dong X, Simon MA, Evans D: Elder self-neglect is associated with increased risk for elder abuse in a community-dwelling population: findings from the Chicago Health and Aging Project. J Aging Health 2013;25:8096.

-39 Dong X, Chang ES, Wong E, Wong B, Simon MA: How do US Chinese older adults view elder mistreatment? Findings from a community-based participatory research study. J Aging Health 2011;23:289-312. 